\title{
HCF behavior of material Tc17 considering surface roughness $\mathrm{Ra}$
}

\author{
Sibo $\mathrm{Gao}^{1, *}$, Wei Yang ${ }^{1}$, Jinlong Wang ${ }^{2}$, Yang Yu${ }^{1}$, Qi Ding ${ }^{1}$, Xiaohan $\mathrm{Gao}^{3}$, and Tian Tian ${ }^{1}$ \\ ${ }^{1}$ Dalian Institute of Measurement and Control Technology, The fifth laboratory, Dalian, China \\ ${ }^{2}$ Dalian Maritime University, Marine Engineering College, Dalian, China \\ ${ }^{3}$ Dalian Ocean University, School of Marine Law and Humanities, Dalian, China
}

\begin{abstract}
Surface scratch has significant influence on the fatigue behavior of Ti-5Al-2Zr-4Mo-4Cr. In this paper, fatigue test with three different surface roughness are conducted, test results are recorded, including test data and fracture characteristics. The distribution of test data is analyzed and the fracture characteristics are discussed according to the change of surface roughness. Study of fatigue behavior of Ti-5Al-2Zr-4Mo-4Cr with surface roughness is significant intheoretical and engineering fatigue study.
\end{abstract}

\section{Introduction}

Surface scratch has a significant effect on the fatigue property of metal material [1-3], titanium alloy titanium alloy is no exception. Ti-5Al-2Zr-4Mo-4Cr is a kind of $\alpha-\beta$ two phase titanium alloy with $\beta$-stable element, also known as Tc17 titanium alloy. It has been widely applied in the marine field for its excellent mechanical property [4-5]: high strength, good corrosion resistance, low relative density, and good high temperature oxidation resistance. Many aerospace mechanical parts are manufactured by Tc17, and in normal conditions, fatigue failure is the most threatening form of failure [6-8].

In actual working practice, a relatively smooth surface is the essential requirement for a mechanical part, and no obvious defect is allowed on the surface. But many failure cases show that, fatigue failure is the most threatening failure form of $\mathrm{Tc} 17$ and it frequently occurs on the surface. The main factor causing the fatigue failure, in such care, should be the surface scratches made in machining process or operating process, which can be quantitatively expressed as the surface roughness. Different surface roughness types will correspond to different surface scratches. So, it is necessary to study and clear how the different surface scratches the Tc17 fatigue failure mechanism and fatigue property, avoid the fatigue failure of Tc17 parts in actual working condition.

Quite a few studies have been carried out to investigate the effect of surface roughness on fatigue failure and the fatigue property of Tc17 titanium alloy. Huang put forward a investigation about the fatigue life dispersion and thermal dissipation for Tc17, the failure probability prediction method is used to evaluate the VHCF dispersion based on the multi scale method and fatigue thermal dissipation analysis

\footnotetext{
*Corresponding author: 284080421@qq.com
} 
Although some investigations have been carried out to study the fatigue failure behavior of TC17, neither the effect of surface roughness on Tc17 fatigue property, nor the Tc17 fatigue property assessment with the consideration of different surface roughness ( $\mathrm{Ra}$ and $\mathrm{Rz}$ ) is studied well. A more detailed and targeted research is carried out in this paper, main research focuses on the fatigue behavior and fatigue property analysis of Tc17 considering different types of surface roughness $\mathrm{Ra}$ and $\mathrm{Rz}$. The designed fatigue tests are carried out with different surface roughness, and the surface roughness ( $\mathrm{Ra}$ and $\mathrm{Rz}$ ) for each specimen is detected and recorded by ZYGO surface profilometer. The test results are recorded, including fatigue life and fatigue loading condition. S-N curves for different surface roughness $\mathrm{Ra}$ are drawn with the combined application of test results and the classic model, to reflect the effect of surface roughness on the fatigue limit of Tc17. The observations of characteristics of the fracture surface are obtained with SEM, and the influence of different surface roughness on the fatigue failure mechanism of Tc17 is well discussed. Further more, the fatigue life prediction models for $\mathrm{Tc} 17$ as a function of $\mathrm{Ra}$ and $\mathrm{Rz}$ are developed respectively, the comparison between theoretical life and the additional test results is carried out to determine which model is more suitable for fatigue life prediction of Tc17.

\section{Two different quantitative representations of surface scratch}

As mentioned above, surface scratches can be quantitatively expressed as the surface roughness, and different surface roughness types will correspond to different surface scratches. In common conditions, surface roughness is quantitatively expressed as two index value: $\mathrm{Ra}$ and $\mathrm{Rz}$, different surface roughness types may have different effectiveness on the fatigue failure of Tc17. Ra means the absolute arithmetic average of the contour offset within the sampling length, and $\mathrm{Rz}$ is the sum of highest and deepest groove depth at the minimum cross-section of the specimen within the sampling length (lr). Thus, Ra is employed as the quantitative representations of different surface scratch types.

According to the fracture mechanics, fatigue crack initiation always prefers the position with small fatigue strength or serious stress concentration. High extent of surface roughness will result in serious stress concentration and weak the fatigue property of TC17 to resist fatigue failure and therefore specifically decline the fatigue strength of the material. Ra has been widely employed to analyze the effect of surface roughness on the fatigue property for its advantages: First, wide expression range, both the surface micro geometry and profile peak of the surface morphology can be reflected by Ra at the same time; Second, simple detection process, the data acquisition of Ra can be conducted out by ZYGO surface profilometer; Third, the theoretical analysis and calculation results tend to be safe.

\section{The fatughe test with different surface scratch types}

\subsection{Material and specimen}

The specimen used in this paper is obtained from the Ti-5Al-2Zr-4Mo-4Cr (TC17 titanium alloy). The chemical compositions of the specimen are displayed in Table.1. The statics mechanical property of TC17 is tested as shown in Tab.2. The heat treatment process of TC17 specimen is: recrystallization annealing, $840^{\circ} \mathrm{C}$ for $1 \mathrm{~h}$, air cooling; solution aging treatment, $800^{\circ} \mathrm{C}$ for $1 \mathrm{~h}$, water cooling and then heat preservation for $8 \mathrm{~h}$, air cooling.

Table 1. The chemical composition.

\begin{tabular}{|c|c|c|c|c|c|c|c|c|c|c|}
\hline $\mathrm{Al}$ & $\mathrm{Sn}$ & $\mathrm{Mo}$ & $\mathrm{Cr}$ & $\mathrm{Zr}$ & $\mathrm{Fe}$ & $\mathrm{C}$ & $\mathrm{N}$ & $\mathrm{H}$ & $\mathrm{O}$ & $\mathrm{Ti}$ \\
\hline 5.0 & 2.0 & 4.0 & 4.0 & 2.0 & 0.07 & 0.01 & 0.01 & 0.001 & 0.12 & $\mathrm{Bal}$ \\
\hline
\end{tabular}


Table 2. Mechanical property of TC17.

\begin{tabular}{|c|c|c|c|c|}
\hline & $\begin{array}{c}\text { Elastic modulus } \\
\mathrm{E}(\mathrm{GP})\end{array}$ & $\begin{array}{c}\text { Tensile strength } \\
\mathrm{Rm}(\mathrm{MPa})\end{array}$ & $\begin{array}{c}\text { Yield strength } \\
\mathrm{Rp} 0.2(\mathrm{MPa})\end{array}$ & $\begin{array}{c}\text { Vickers hardness HV } \\
\text { (kgf } / \mathrm{mm} 2)\end{array}$ \\
\hline $\mathrm{TC} 17$ & 111.5 & 1108.5 & 1060.5 & 356 \\
\hline
\end{tabular}

The shape of the specimen is shown in Fig.1. Hourglass type test specimen is employed in this test, the geometric dimensions of the specimen are calculated according to the elasticity modulus and density of TC17.

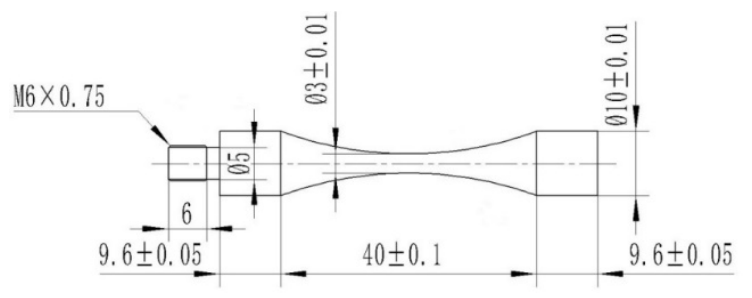

Fig. 1. The specimen.

\subsection{The surface scratches detection}

In order to investigate the influence of different surface scratches on the fatigue property of $\mathrm{TC} 17$, the specimen with different surface roughness are used in the fatigue test. Comparing to $\mathrm{Rz}, \mathrm{Ra}$ is relatively controllable, thus with the comprehensive consideration of actual working condition, processing condition and the test requirement, the average surface roughness $\mathrm{Ra}$ of the specimen is divided into three groups as: Group1, Ra1 $\approx 0.25 \mu \mathrm{m}$; Group2, $\mathrm{Ra} 2 \approx 0.6 \mu \mathrm{m}$; Group3, Ra3 $\approx 1.2 \mu \mathrm{m}$. According to the characteristic of surface roughness $\mathrm{Rz}$, it is hard to make the values of surface roughness $\mathrm{Rz}$ in the same or similar range, so it is a different value and unique feature for each specimen. With ZYGO surface profilometer, the surface roughness ( $\mathrm{Ra}$ and $\mathrm{Rz}$ ) of the specimen is measured, the examples are shown in Fig.2.

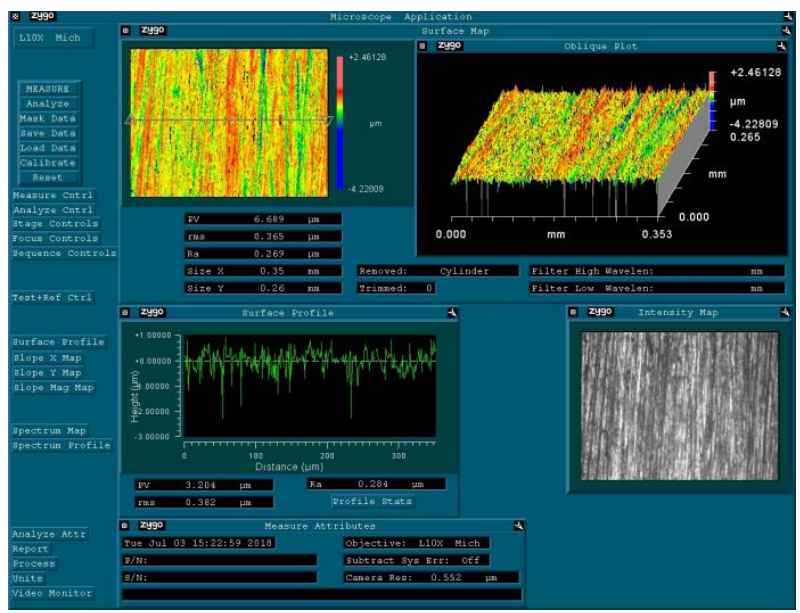

Fig. 2. The examples of the surface roughness measurement.

\subsection{Test method}

Symmetrical cyclic load is employed in the test, the stress ratio $r=-1$ and mean stress is zero. The maximum stress amplitude is $675 \mathrm{MPa}$ and the minimum one is $615 \mathrm{MPa}$, the interval is 
$15 \mathrm{MPa}$. Air cooling is employed to avoid the influence of temperature rising. Both stress amplitude and the relevant fatigue life will be recorded. The microstructure and morphology of the fracture surface are observed by scanning electron microscope (SEM), and the chemical compositions of the fatigue failure initiation region is identified with the energy spectrum analysis. All these results and test data will be recorded and used to analyze the influence of different surface scratches on TC17 fatigue failure.

\section{Test results}

\subsection{The test data distribution}

The test data are recorded, including fatigue stress amplitude $\Delta \sigma$ and fatigue life $\mathrm{Nf}$, as shown in Fig.3. The fatigue life mainly concentrated in the high-cycle fatigue $(105<\mathrm{Nf}<107)$, only five specimen have fatigue life more than 107 cycles. Three specimens don't fracture, and the rest specimens all have surface fatigue failure, including the specimen in very-high cycle regime.

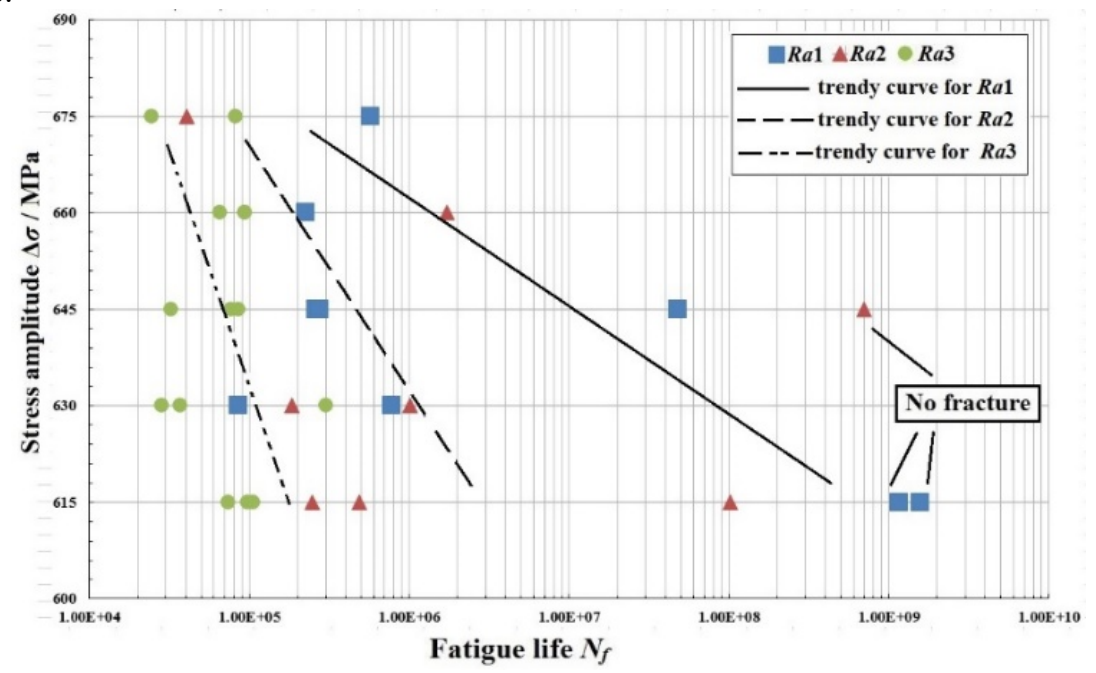

Fig. 3. The test data.

According to Fig.3, some characteristics of the TC17 test result can be obtained: first, with a certain stress amplitude value, there is a negative relationship between fatigue life and surface scratch, with the decrease of surface roughness, the fatigue life increases, in another words, small stress amplitude will cause the fatigue failure of TC17 specimen with big surface scratch; second, there are three qualitative distribution trend curves between stress amplitude $\Delta \sigma$ and fatigue life $\mathrm{Nf}$ are drawn in Fig.3, slopes of the curves increase with the decreases of surface roughness, a small change of the stress amplitude will result in a big improvement of fatigue life; third, the second one can also be expressed as: with the decrease of the surface roughness, the dispersion of the test data distribution becomes bigger. For Ra3, in the range of the stress amplitude from $615 \mathrm{MPa}$ to $675 \mathrm{MPa}$, the relevant fatigue life is from about $3 \times 104$ cycles to $3 \times 105$ cycles. But as the surface roughness decreases to Ra1, the fatigue life distribution becomes more discrete, the changing range of the fatigue for Ra1 is from 105 cycles to 109 cycles.

Something important should be noticed that the straight line in Fig. 3 only shows the qualitative distribution trend of the test data and the reflection of S-N curve changing trendy. It doesn't mean the surface roughness and the fatigue life satisfy a linear relation statistically. 
And the S-N curve models of TC17 for different surface roughness will be proposed respectively to in chapter 4 , which will be used to quantitative express the effect of surface scratch on TC17 fatigue property and fatigue failure behavior.

\subsection{The fracture characteristics observations}

As discussed above, surface scratches have a significant influence on the fatigue property of TC17. And the test results show that most failure occurs in high cycle regime, the morphology characteristics around the fatigue crack initiation site of some specimens in high cycle regime are detected with SEM, as shown in Fig.4. After that, energy spectrum analysis is carried out to clear the chemical composition of the crack initiation site to determine the type of defect that causes the fatigue failure.
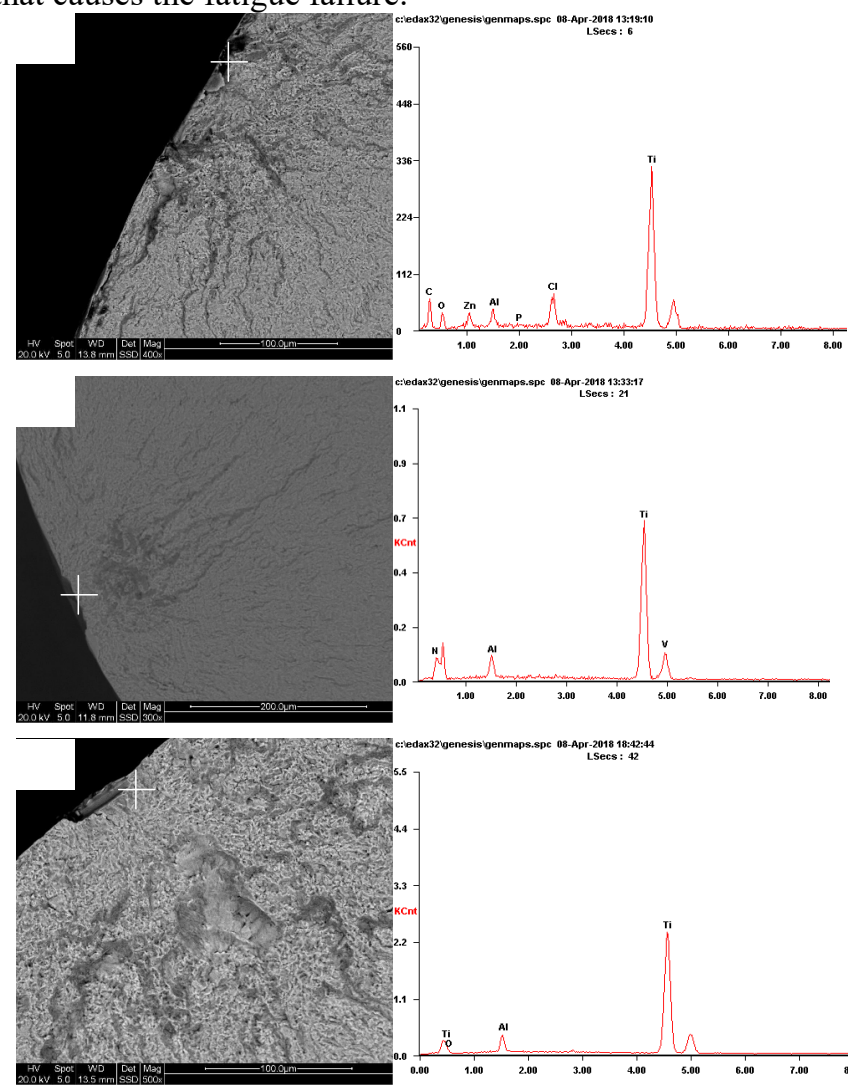

Fig. 4. The fatigue crack initiation sites.

Fig.4 (a) is the observation for Ra3, Fig. 4 (b) is the observation for Ra2 and Fig. 4 (c) is the observation for Ra1, these observations are all under the same stress amplitude. It is clear in Fig. 4 that no GBF region or "fish-eye" is observed, but obvious radial striations are clear detected on the fracture surface. The radial striation is the most significant characteristic of the surface failure, and these striations propagate from the fatigue crack initiation site to the boundary between the stable propagation region and the instable propagation region.

The energy spectrum analysis results show that, the main chemical composition in the initiation site is $\mathrm{Ti}$, and the content of the other chemical element is very low. This implies that the fatigue crack initiates from the surface matrix material, no inclusion or other chemical element affect the fatigue failure. Combining the observations and energy spectrum analysis 
results, it is clear that the surface scratch should be allocated as the primary factor of the fatigue failure.

Another point from Fig.4(a) to Fig.4(c) show that the surface scratch has an influence on the fatigue crack propagation. On the crack propagation stage, the plastic deformation of the matrix material around the fatigue crack progresses faster and faster, and the crack propagation procedure is promoted. This result in the high strain rate of fatigue crack propagation for big surface roughness. And it is difficult for matrix material to timely recover under high strain rate of fatigue crack propagation, so the fatigue crack continuous to propagate to failure and radial striation is left on the path of the fatigue crack propagation. So, as shown in Fig. 4(a),Fig.4(b) and Fig.4(c), with the increasing of the surface roughness from Ra1 to Ra3, the radial striation is observed and the striation becomes more obvious.

\section{Conclusioins}

A few conclusions are drawn from this research:The distribution of fatigue life is mainly concentrated in the high-cycle fatigue area even with a relatively low stress amplitude for Ti$5 \mathrm{Al}-2 \mathrm{Zr}-4 \mathrm{Mo}-4 \mathrm{Cr}$; With the effect of surface micro-scratch, the surface fatigue failure is the main failure type of most specimens for Ti-5 Al-2Zr-4Mo-4Cr in HCF.

\section{References}

1. Wu SC, Xu ZW, Liu YX, Kang GZ, Zhang ZX. On the residual life assessment of highspeed railway axles due to induction hardening. International Journal of Rail Transportation ; 6(4): 218-232(2018)

2. Wu SC, Liu YX, CH Li, Kang GZ, Liang SL. On the fatigue performance and residual life of intercity railway axles with inside axle boxes. Eng Fract Mech;197: 176-191(2018)

3. Wu SC, Li CH, Luo Y, Zhang HO, Kang GZ. A uniaxial tensile behavior based fatigue crack growth model. Int J Fatigue;131: 105324.(2020)

4. Guo SJ. Research on Very High Fatigue Life Distribution and High Reliability of Structural Components, [Ph.D thesis]. Nanjing: Nanjing University of Aeronautics and Astronautics(2006)

5. He S, Yang Q, Min XL. Influence of shot peening on fatigue property of TC17 titanium alloy. Heat Treatment of Metals;43(6): 159-161(2018)

6. Li JK, Liu YJ, Wang QY, Hou F. High-cycle rotate bending fatigue behavior of TC17 at elevated temperature. Journal of Sichuan University (Engineering Science Edition) ; 46(2): 198-202(2014)

7. Huang ZY, Liu HQ, Wang C, Wang QY. Fatigue life dispersion and thermal dissipation investigations for titanium alloy TC17 in very high cycle regime. Fatigue Fract Eng M; 38(11): 1285-1293(2015)

8. Gao C, Cheng L, Peng H, Shen JS, Qiu CL, Liu YJ. Investigation of ultra-high cycle fatigue behavior of TC17 alloy at a frequency of $20 \mathrm{kHz}$. Journal of Aerospace Power, 24(4): 811-816(2012) 